\title{
EFEKTIFITAS MODEL PEMBELAJARAN CCM-CCA UNTUK MEMFASILITASI PERUBAHAN KONSEP GAYA PADA MAHASISWA
}

\author{
Muh. Makhrus" ${ }^{* 1}$, Wahono Widodo², Rudiana Agustini² \\ ${ }^{1}$ Program Studi Pendidikan Fisika, Universitas Mataram \\ ${ }^{2}$ Pendidikan Sains, Program Pascasarjana Universitas Negeri Surabaya \\ *Email: makhrus.fkip@unram.ac.id
}

\begin{abstract}
This study aims to examine the effectiveness of the CCM-CCA learning model that has been validated by physicist education through Focused Group Discussions (FGD) activities, and the validation results are valid in content and construct. The research design used follows the Education Research and Development method. The development of models starting from designing the model until implementing the model. Test the effectiveness of the model measured by the results of analysis of observational data and interview results on the occurrence of conceptual changes in students. Observation and interview data refers to the thought process experienced by students as a condition for conceptual change. The results of the study showed that students who were the subjects of the study experienced the four (4) thought processes that were the conditions for conceptual change. These results indicate that the CCM-CCA learning model is an effective learning model for facilitating the occurrence of student conceptual changes from wrong conceptions into scientific conceptions (physicist conception) about the concept of force.
\end{abstract}

Keywords: Effectiveness, CCM-CCA Learning Model, Concept Change, Force

\section{PENDAHULUAN}

Fisika Dasar merupakan mata kuliah yang lebih banyak memerlukan pemahaman. Mata kuliah ini berisi tentang materi-materi fisika yang umumnya telah diajarkan di sekolah menengah. Mahasiswa mengikuti perkuliahan dengan memiliki pengalaman dan pengetahuan yang berhubungan dengan materi fisika yang akan diajarkan. Fakta ini memungkinkan mahasiswa memiliki prakonsepsi, konsepsi alternatif, sains anakanak, ide-ide intuitif, dan gagasan informal yang disebut miskonsepsi (Demircioglu, Ayas, \& Demircioglu, 2005: Unal, Costu, \& Ayas, 2010), dan hal ini dapat menyebabkan kesulitan pada saat mempelajari suatu konsep. Miskonsepsi merupakan gagasangagasan yang muncul dalam pikiran mahasiswa yang bersifat pribadi dan umumnya gagasan tersebut tidak bersifat ilmiah. Miskonsepsi juga dapat diperoleh dari pengalaman yang berbeda-beda dan sumber informasi yang tidak akurat. Hal ini menjadi dasar yang buruk bagi siswa dalam mengkonstruksi pengetahuan (Silung et al. 2016). Mahasiswa seringkali masih memegang (meyakini) pengetahuan terdahulu (di sekolah) atau konsepsi-konsepsi mengenai dunia natural ketika memasuki kelas (Tomita, 2008). Konsepsi-konsepsi ini akan mempengaruhi bagaimana mahasiswa akan memahami pengalaman-pengalaman formal di perkuliahan. Pengetahuan terdahulu (di sekolah) akan dapat menyediakan sebuah fondasi yang baik dalam pembelajaran di perkuliahan, sedangkan konsepsi-konsepsi yang lain mungkin akan bertentangan dengan pengetahuan ilmiah yang diterima pada saat itu.

Smith et al. (1993) menyatakan bahwa miskonsepsi berasal dari pembelajaran mahasiswa sebelumnya baik di kelas atau dari interaksi dengan dunia sosial dan fisika. Pandangan ini dapat dilihat dari keyakinan mengenai miskonsepsi "gaya menyebabkan terjadinya sebuah gerak" yang tertanam dalam pengalaman-pengalaman motorik ketika mahasiswa mendorong ataupun menarik benda-benda. 
Pembelajaran fisika seharusnya dititikberatkan pada upaya penggantian miskonsepsi-miskonsepsi yang dialami mahasiswa dengan konsep para ahli (konsep ilmiah). Hal ini dapat dilakukan melalui pembelajaran konfrontasional dengan cara mengkonfrontasikan miskonsepsimiskonsepsi yang dialami mahasiswa dengan konsep para ahli pada saat melakukan interaksi sosial di kelas, karena konfrontasi dan penggantian miskonsepsi tidak dapat dipisahkan (Smith et al. 1993). Model perubahan konseptual menyatakan bahwa mahasiswa yang datang ke kelas akan disertai dengan miskonsepsi-miskonsepsi mengenai fenomena natural dan miskonsepsi-miskonsepsi tersebut haruslah diungkapkan dan dikonfrontasikan dengan penjelasan atau pendemonstrasian contohcontoh yang berlawanan serta koreksi dengan menyediakan sebuah konsep yang lebih general yang akan diterima dan dipahaminya (Cakir, 2008). Model pembelajaran perubahan konseptual membuat siswa lebih memahami konsep secara mendalam agar dapat bermanfaat bagi kehidupannya. Model ini menuntut guru lebih banyak berperan sebagai pengarah pembentukan konsep ilmiah, sehingga guru lebih banyak berperan sebagai fasilitator, negosiator dan konfrontator (Pebriyanti et al. 2015). Tujuannya adalah untuk membimbing mahasiswa ke arah pandangan-pandangan ilmiah terkini dan menghubungkan ke skema kognitifnya. Hal ini sesuai dengan penelitian terbatas terhadap efek menggunakan model perubahan konseptual melalui demonstrasi (Azizoglu, 2004), di mana demonstrasi merupakan metode yang efektif untuk meningkatkan pemahaman konseptual mahasiswa.

Penelitian pada pembelajaran telah menunjukkan bahwa kesalahan konsep menghambat prestasi mahasiswa. Kesalahan konsep ini sering didasarkan pada pengalaman pribadi dan sulit untuk berubah ke pemahaman konten ilmiahnya (Gelman dan Gallistel 1986; Wellman 1990) dalam Shaw et al. (2008). Permasalahan ini juga terjadi pada mahasiswa PMIPA FKIP Universitas Mataram yang menempuh mata kuliah fisika dasar. Mahasiswa memiliki kecenderungan yang kuat untuk bertahan dengan konsep-konsep yang telah dimiliki, terbukti bahwa konsep tersebut telah diyakini kebenarannya sejak di sekolah menengah dan pada saat perkuliahan pun mereka tetap bertahan dengan konsepkonsep yang telah diyakini kebenarannya tersebut. Fakta ini selaras dengan hasil studi pendahuluan (pre-leminary study) yang dilakukan di program studi Pendidikan Fisika PMIPA FKIP Universitas Mataram dan program studi Pendidikan Sains FMIPA Universitas Negeri Surabaya. Studi pendahuluan tersebut memiliki tujuan untuk mengidentifikasi konsepsi-konsepsi awal (pre-conception) yang dimiliki mahasiswa terhadap konsep gaya dan mendeskripsikan kepercayaan mahasiswa terhadap kebenaran suatu konsep yang terkait dengan konsep gaya. Hasil studi pendahuluan pada ke dua universitas tersebut menunjukkan bahwa mahasiswa telah mengalami miskonsepsi pada konsep gaya, yakni tentang konsep benda diam, kelembaman benda, benda yang bergerak ke atas, gaya gesekan, dan keberlakuan terhadap Hukum I dan III Newton (Makhrus, 2013).

Konflik kognitif memainkan sebuah peran atau efek penting dalam perubahan konseptual. Lee et al. (2003) dan Kwon (1997) dalam Baser (2006: 99), mengatakan tentang kebutuhan akan pentingnya konflik kognitif untuk membuat perubahan konseptual terjadi. Model perubahan konseptual dengan pendekatan konflik kognitif atau conceptual change model with cognitive conflict approach yang disingkat menjadi CCM-CCA adalah model pembelajaran yang dikembangkan dengan 
tujuan untuk memfasilitasi perubahan konsep gaya pada mahasiswa dengan cara mereduksi miskonsepsi mahasiswa pada mata kuliah Fisika Dasar.

Tujuan penelitian ini adalah menguji keefektifan model pembelajaran CCMCCA. Keefektifan model tersebut akan ditunjukkan dengan peningkatan perubahan konseptual yang terjadi pada mahasiswa setelah pembelajaran dengan CCM-CCA pada konsep gaya. Secara spesifik pertanyaan penelitian yang akan dijawab dalam penelitian ini adalah: bagaimana proses berpikir yang dialami mahasiswa Group Pretest-Posttest Design (Fraenkel, et al., 2012: 269). Langkahlangkah penelitian terdiri atas tiga langkah, yakni: 1) Pemberian pre-test untuk mengetahui kemampuan awal dan miskonsepsi yang terjadi pada subyek penelitian, 2) Melaksanakan kegiatan pembelajaran melalui model perubahan konseptual dengan pendekatan konflik kognitif, dan 3) Penilaian hasil pembelajaran (post-test). Untuk mengetahui proses berpikir yang dialami mahasiswa sebagai syarat terjadinya perubahan konseptual dilakukan pengamatan terhadap 4 mahasiswa yang dikelompokkan menjadi empat kategori, yaitu (1) mahasiswa dengan konflik kognitif tinggi dan beban miskonsepsi tinggi (M1), (2) mahasiswa dengan konflik kognitif tinggi dan beban miskonsepsi rendah (M2), (3) mahasiswa dengan konflik kognitif rendah dan beban miskonsepsi rendah (M3), dan (4) mahasiswa dengan konflik kognitif yang rendah dengan beban miskonsepsi tinggi (M4).Perubahan konseptual yang terjadi pada mahasiswa akan diamati dengan observasi langsung dan wawancara pada saat terjadinya pembelajaran oleh observer. Data yang merupakan hasil pembelajaran dianalisis untuk melihat keefektifan model pembelajaran CCM-CCA. sebagai syarat terjadinya perubahan konseptual?

\section{METODE PENELITIAN}

Model pembelajaran CCM-CCA yang telah valid secara isi dan konstruk serta menunjukkan adanya kebutuhan (need), kebaruan (state of the art), memiliki landasan yang kuat, dan terdapat konsistensi antar komponen model (Makhrus, 2018) diujicobakan pada 30 mahasiswa program studi pendidikan fisika Universitas Mataram pada mata kuliah fisika dasar tentang konsep "gaya" dengan desain penelitian One

Beban miskonsepsi ditentukan dari hasil uji awal (pretest) yang dilengkapi dengan instrumen CRI (Certainty of Response Index) yang digunakan untuk menentukan kualitas kepastian jawaban responden. Besarnya konflik kognitif ditentukan dari instrumen pengukuran besarnya konflik kognitif berupa lembar check list yang diisi mahasiswa setelah mengerjakan pretest dan didukung hasil wawancara.

Perubahan konseptual yang terjadi pada mahasiswa akan diamati secara langsung dengan menggunakan instrumen lembar pengamatan pada saat pembelajaran dan wawancara langsung setelah pembelajaran. Instrumen lembar pengamatan mengacu pada proses berpikir yang harus dialami mahasiswa sebagai syarat terjadinya perubahan konseptual (Posner et al., 1982:214), yaitu: (1) harus ada ketidakpuasan (dissatisfaction) dengan konsepsi ada, (2) suatu konsepsi baru harus dapat dimengerti atau memiliki kejelasan (intelligibility), (3) suatu konsepsi baru harus nampak pada awalnya masuk akal atau memiliki logika (plausibility), dan (4) suatu konsep baru menyarankan kemungkinan suatu program riset yang penuh keberhasilan (fruitfulness).

Persentase besarnya proses berpikir yang dialami mahasiswa, diperoleh dari nilai 
akhir x $100 \%$. Nilai akhir adalah jumlah skor / jumlah deskriptor tiap proses berpikir yang dialami mahasiswa pada saat pembelajaran.

Tabel 1. Kriteria perubahan konseptual mahasiswa

\begin{tabular}{c|c}
\hline Kategori & Persentase \\
\hline Rendah & $0-25$ \\
\hline Sedang & $25<\mathrm{P} \leq 50$ \\
\hline Tinggi & $50<\mathrm{P} \leq 75$ \\
\hline Sangat Tinggi & $75<\mathrm{P} \leq 100$ \\
\hline
\end{tabular}

Pembelajaran dengan CCM-CCA dilaksanakan sebanyak 5 pertemuan, yaitu: pertemuan pertama (menganalisis gaya-gaya yang bekerja pada benda yang rihat/diam), pertemuan kedua (besaran yang mempengaruhi kelembaman suatu benda), pertemuan ketiga (menganalisis gaya-gaya yang bekerja pada benda yang bergerak ke atas setelah dilemparkan ke atas), pertemuan ke empat (menganalisis pengaruh tingkat kehalusan dan kekasaran permukaan benda terhadap besarnya gaya gesek), dan pertemuan ke lima (menganalisis gaya-gaya yang bekerja pada benda yang ditarik oleh tali yang horisontal sedemikian rupa sehingga benda bergerak pada lantai dengan kecepatan tetap). Tabel 2 di bawah ini adalah contoh pembelajaran melalui model perubahan konseptual dengan pendekatan konflik kognitif.

Tabel 2. Pembelajaran melalui model pembelajaran CCM CCA pada pertemuan ke tiga

Fase I: Menyajikan konflik kognitif Meminta mahasiswa melakukan demontrasi seperti yang ada di lembar kerja mahasiswa, kemudian bertanya kepada mahasiswa, apakah yang membuat bola setelah dilemparkan dapat bergerak ke atas, berhenti, dan bergerak turun ke bawah?

Fase II: Menentapkan hasil dan posisi Meyakinkan mahasiswa menjadi sadar mengenai pemikiran mereka sendiri dengan merespon pertanyaan di atas, atau dengan mencoba untuk memecahkan masalah atau tantangan dengan cara menggambar gaya-gaya yang terkait dengan demontrasi yang dilakukan oleh dosen.

Fase III: Mengekspos kepercayaan

Membimbing mahasiswa melakukan sharing dan mendiskusikan gagasangagasan mereka, prediksi, dan alasanalasan mereka dengan teman sekelas mereka sebelum mereka mulai menguji gagasan dengan aktivitas, seperti menggambar gaya-gaya yang bekerja pada bola saat bergerak ke atas, berhenti, dan bergerak turun ke bawah.

Fase IV: Menciptakan konflik kognitif

Menantang mahasiswa untuk mengkonfrontasikan pemikiran mereka terkini melalui pengalaman-pengalaman kolaboratif yang menantang pra konsepsi mereka dengan mengkonsultasikan sumber-sumber (buku rujukan) dan mengumpulkan data-data melalui penyelesaikan masalah yang terdapat pada lembar kerja mahasiswa. Misalnya dengan menyampaikan bahwa bola bergerak ke atas bukan karena daya dorong yang diberikan tangan pada saat melempar tetapi akibat dari bola yang dipercepat oleh tangan sampai mencapai kecepatan yang akan merupakan kecepatan awal pada saat bola lepas dari tangan.

Fase V: Mengakomodasi dan memperluas konsep-konsep

Mahasiswa dalam kelompok mengakomodasi sebuah pandangan, konsep atau skill baru dan memperluas konsep dengan menyimpulkan, mendiskusikan, berdebat, dan menginkorporasikan informasi baru terkait dengan keadaan bola yang dilemparkan ke atas.

Mahasiswa mengaplikasikan dan membuat hubungan antara konsep baru atau skill dengan situasi-situasi dan gagasan-gagasan lain. Misalnya tentang konsep momentum, bahwa momentum mempunyai hubungan yang langsung dengan kecepatan dan merupakan besara vektor yang searah dengan kecepatan.

Fase VI: Fase pengujian masalah atau penyelesaian 
Dosen menawarkan pembahasan rinci dari fenomena yang membingungkan, dan menunjukkan bagaimana konsepsi ilmiah dapat berlaku dengan melakukan demonstrasi pengetahuan maupun kegiatan ilmiah. Misalnya dengan menjelaskan bahwa momentum mempunyai hubungan yang langsung dengan kecepatan dan merupakan besara vektor yang searah dengan kecepatan. Makin besar kecepatan bola, makin besar momentumnya. Kalau kecepatan berkurang, maka otomatis momentum bola juga berkurang. Kalau benda rihat/diam, berarti momentumnya juga nol. Oleh karena momentumlah, saat lepas dari tangan, bola masih bisa bergerak naik. Pada saat kita menggerakkan tangan untuk melemparkan bola ke atas, kita memberikan perubahan momentum pada bola. Momentum bola bertambah dari mula-mula nol menjadi suatu jumlah tertentu. Waktu bola lepas dar tangan, bola tetap memiliki momentum yang diperolehnya dari tangan kita. Dalam gerakannya ke atas, momentum bola berkurang akibat dari perlambatan yang disebabkan oleh gravitasi dan gesekan udara. Jadi yang berkurang adalah momentum bola bukan gaya ke atas.

Fase VII: Evaluasi

Meminta mahasiswa untuk melakukan penilaian terhadap kebenaran konsep yang mereka miliki dan menerapkan konsepkonsep ilmiah untuk masalah baru di mana prasangka mereka tidak berlaku, yaitu dengan menyelesaikan masalahmasalah yang berkaitan dengan penerapan hokum II Newton dalam kehidupan sehari-hari.

\section{HASIL DAN PEMBAHASAN}

Hasil pengamatan terjadinya perubahan konseptual pada ke empat mahasiswa menunjukkan terjadinya perubahan konseptual yang tinggi (T) pada pembelajaran di pertemuan pertama (menganalisis gaya-gaya yang bekeja pada benda yang rihat/diam) dan pertemuan kedua (besaran yang mempengaruhi kelembaman suatu benda).Sedangkan di pertemuan ketiga (menganalisis gaya-gaya yang bekerja pada benda yang bergerak ke atas setelah dilemparkan ke atas), pertemuan ke empat (menganalisis pengaruh tingkat kehalusan dan kekasaran permukaan benda terhadap besarnya gaya gesek), dan pertemuan ke lima (menganalisis gaya-gaya yang bekerja pada benda yang ditarik oleh tali yang horisontal sedemikian rupa sehingga benda bergerak pada lantai dengan kecepatan tetap) menunjukkan terjadinya perubahan konseptual yang sangat tinggi (ST). Hal ini menunjukkan bahwa ke empat mahasiswa pada umumnya masih memiliki konsepsi yang salah di awal pembelajaran atau bahkan memiliki miskonsepsi tentang konsep yang diajarkan. Pembelajaran dengan model perubahan konseptual dengan pendekatan konflik kognitif telah mampu membuat mahasiswa mengalami semua proses berpikir yang menjadi syarat terjadinya perubahan konseptual, yaitu adanya ketidakpuasan terhadap konsepsi awal yang dimiliki (dissatisfaction), adanya kejelasan terhadap konsepsi yang baru (intelligibility), adanya logika terhadap konsepsi yang baru (plausibility), dan adanya keberhasilan terhadap konsepsi yang baru yang harus dihargai (fruitfulness).

Pada pembelajaran di pertemuan ke tiga tentang menganalisis gaya-gaya yang bekerja pada bola yang dilemparkan ke atas, di pertemuan ke empat tentang menganalisis pengaruh tingkat kehalusan dan kekasaran permukaan benda terhadap besarnya gaya gesek dan di pertemuan ke lima tentang menganalisis gaya-gaya yang bekerja pada benda yang ditarik oleh tali yang horisontal sedemikian rupa sehingga benda bergerak pada lantai dengan kecepatan tetap, perubahan konseptual yang terjadi pada mahasiswa adalah sangat tinggi (ST). Hal ini dikarenakan keempat mahasiswa memang memiliki konsepsi yang benar-benar salah. Pada pertemuan ke tiga, mahasiswa 
menganggap pada bola yang bergerak ke atas setelah dilemparkan adalah memiliki gaya ke atas yang merupakan gaya dorong yang menyebabkan bola bergerak ke atas. Mereka tidak pernah mendapatkan pembelajaran yang menjelaskan bahwa kecepatan yang menyebabkan bola bergerak ke atas.

Kemudian pada pembelajaran di pertemuan ke empat, ke empat mahasiswa mempercayai bahwa balok kayu yang ditarik dipermukaan kayu yang semakin halus akan memiliki gaya gesek yang semakin kecil, padahal sebaliknya akan memiliki gaya gesek yang semakin besar. Begitu juga pada pembelajaran di pertemuan ke lima, ke dua mahasiswa mempercayai hanya ada 4 buah gaya atau dua pasang gaya saja yang bekerja pada balok kayu yang ditarik tali horisontal sedemikian rupa sehingga benda bergerak pada lantai dengan kecepatan tetap, di mana sepasang gaya tersebut merupakan pasangan gaya yang menunjukkan keberlakuan hukum I Newton yang menyebabkan balok kayu bergerak dengan kecepatan tetap. Akan tetapi ketika ditanyakan tentang keberlakuan hukum III Newton, mereka tidak bisa menyebutkan karena mereka tidak mengetahui gaya-gaya lain yang bekerja pada balok kayu tersebut. Keadaan ini yang menyebabkan terjadinya ketidakpuasan terhadap konsepsi yang lama dan kedua mahasiswa mulai tertarik untuk memecahkan masalah yang ada dengan mengkonfrontasikan konsepsi yang lama dengan konsepsi yang baru melalui percobaan dan sumber-sumber rujukan yang ada. Sedangkan pada pembelajaran di pertemuan pertama tentang menganalisis gaya-gaya yang bekerja pada benda yang rihat (diam) dan di pertemuan ke dua tentang menganalisis besaran yang mempengaruhi kelembaman suatu benda, perubahan konseptual yang terjadi pada kedua mahasiswa adalah tinggi, hal ini dikarenakan kedua mahasiswa sebenarnya telah memiliki konsepsi yang benar tetapi ketika diberikan pandangan yang berbeda mahasiswa menjadi ragu bahkan meninggalkan kepercayaan terhadap konsepsi lama tersebut. Misalnya, ke dua mahasiswa sudah memahami bahwa pada buku yang di taruh di telapak tangan dan digantungkan di pegas bekerja dua buah gaya yang besarnya sama dan berlawanan arah, tetapi ketika buku di tambah kedua mahasiswa menjadi ragu akan kebenaran konsepsi yang dimiliki. Begitu juga pada besaran yang mempengaruhi kelembaman benda. Ke empat mahasiswa menjadi ragu bahwa massa adalah satusatunya besaran yang mempengaruhi kelembaman suatu benda ketika melihat perlakuan yang diberikan pada kelereng.

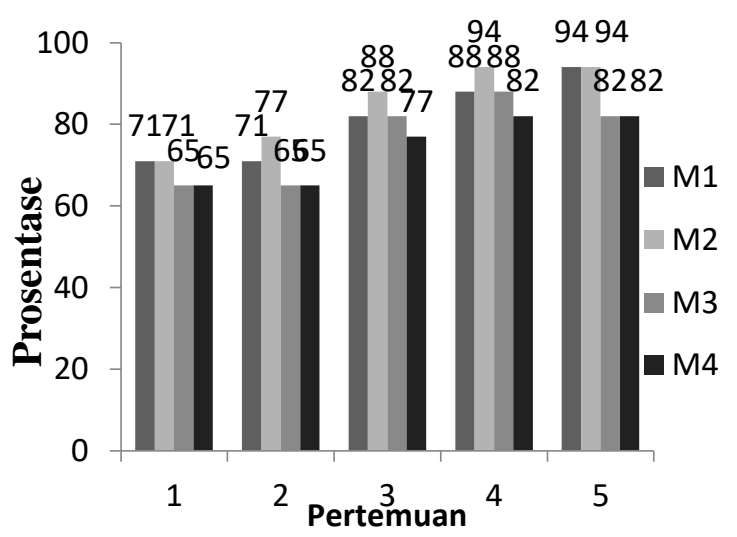

Gambar 1. Hasil pengamatan terjadinya perubahan konseptual

Berdasarkan hasil pengamatan, dapat diketahui bahwa persentase terjadinya perubahan konseptual yang terjadi pada mahasiswa yang memiliki konflik kognitif tinggi (M1 dan M2) adalah lebih besar dari mahasiswa yang memiliki konflik kognitif rendah (M3 dan M4), seperti yang nampak pada Gambar 1. Berdasarkan Gambar 1 dapat diketahui bahwa ke empat mahasiswa terjadi perubahan konseptual yang tinggi (T) pada pertemuan 1 dan pertemuan 2 dan terjadi perubahan konseptual yang sangat tinggi (ST) pada pertemuan 3, pertemuan 4 , dan pertemuan 5 .

Pada saat fase awal pembelajaran, 
ketika dosen menyampaikan konteks masalah melalui demonstrasi sederhana atau informasi pengetahuan yang kontradiksi dengan konsepsi awal yang dimiliki mahasiswa, maka pada saat itu ke empat mahasiswa langsung merasakan ketidakpuasan dengan konsepsi yang ada (dissatisfaction). Mahasiswa mengalami keadaan tidak setimbang dalam struktur kognitifnya akibat adanya kontradiksi antara pengalaman dan informasi lama (kepercayaan yang salah) yang mereka miliki dengan informasi baru yang dihadapi sebelum terjadinya proses akomodasi. Hal ini selaras dengan yang dikatakan Byun, T. \& Lee, G. (2011), bahwa demonstrasi yang efektif untuk menciptakan konflik kognitif, harus cukup sederhana sehingga maha (siswa) dapat dengan mudah memahami situasi dan pertanyaan yang berkaitan dengan demonstrasi. Konflik kognitif (disequilibrium) yang terjadi pada mahasiswa di awal pembelajaran tersebut memotivasi mereka untuk mencoba menyelesaikan konflik. Berlyne (1960, 1963, 1965) dalam Lee et al. (2003) mengatakan bahwa konflik konseptual memiliki potensi gairah tinggi, memotivasi peserta didik untuk mencoba mengatasinya dengan mencari informasi baru atau dengan mencoba untuk mereorganisasi pengetahuan yang telah dimiliki. Keadaan ini mengakibatkan pembelajaran berjalan dengan baik, mahasiswa termotivasi untuk menemukan kejelasan terhadap konsepsi yang ada (intelligibility). Mahasiswa mencoba mengintegrasikan informasi baru yang diperoleh dalam pembelajaran ke dalam skema yang sudah terbentuk yang akan berguna untuk memahami permasalahan yang ada dalam pembelajaran. Peserta didik membangun sebuah model awal dan mengintegrasikan informasi baru ke dalam model untuk membuat tampilan model dan berfungsi seperti masalah (Jonassen et al. 2005). Hal ini berfungsi membantu mahasiswa dalam mengubah skema lama (pembentukan skema baru) untuk menyesuaikan dengan informasi baru, di mana konsep baru yang diadopsi tersebut mempunyai kemampuan memecahkan permasalahan yang dihasilkan oleh konsep lama (plausability). Proses berpikir ini telah memotivasi mahasiswa memperluas konsep yang telah diperoleh dalam pembelajaran dengan cara mengaplikasikan dan membuat hubungan antara konsep baru atau skill dengan situasi-situasi dan gagasan-gagasan lain dan menantang mahasiswa untuk menyampaikan hasilnya dalam diskusi kelas agar mahasiswa lain dapat memberikan tanggapannya. Pembelajaran akan melibatkan pembangunan model-model mental (schema) yang berisikan informasi baik yang telah ada maupun yang baru. Semakin kaya link-link antara pengetahuan yang ada dan yang baru, maka akan semakin dalam pengetahuan serta akan lebih siap untuk diaplikasikan ke situasi-situasi baru (Wirth, Karl R. \& Perkins, Dexter., 2008). Pada akhirnya, setelah mengadakan penyelidikan terhadap permasalahan dengan panduan lembar kerja mahasiswa, berdiskusi, berdebat, dan menyimpulkan serta adanya pembahasan rinci yang diberikan oleh dosen, mahasiswa telah mengalami keadaan setimbang karena masalah yang dihadapi sudah ditemukan jawabannya setelah terjadinya proses akomodasi (fruitfulness).

Proses berpikir di atas telah terjadi pada empat orang mahasiswa selama proses pembelajaran dari pertemuan pertama sampai pertemuan kelima, bahkan berdasarkan Gambar 2 dapat diketahui, bahwa persentase terjadinya perubahan konseptual yang terjadi pada mahasiswa yang memiliki konflik kognitif tinggi adalah lebih besar dari mahasiswa yang memiliki konflik kognitif rendah. Hal ini terjadi karena mahasiswa yang mimiliki konflik kognitif tinggi memiliki kecenderungan 
pada dirinya terjadi ketidakseimbangan struktur kognitif yang lebih kuat dari mahasiswa yang memiliki konflik kognitif rendah, sehingga mahasiswa tersebut lebih tertantang untuk membuktikan kebenaran konsepsi yang baru melalui percobaan dan lebih gigih untuk mengkonsultasikan kebenaran konsepsi baru tersebut dengan sumber-sumber rujukan yang ada (Makhrus, 2014). Melalui strategi konflik kognitif, siswa di hadapkan pada situasi yang bertentangan dengan konsepnya, kemudian di arahkan pada percobaan atau demonstrasi untuk membuktikan kebenaran konsep tersebut. Dalam pembelajaran ini siswa diberikan kesempatan untuk mengungkapkan konsepsinya dan mengkritisi yang berbeda dengan konsepsinya (Tuqalby et al. 2017).

Hasil pengamatan terhadap proses berpikir yang dialami kedua mahasiswa selama pembelajaran tersebut selaras dengan hasil wawancara yang dilakukan oleh dosen/peneliti terhadap mereka ketika pembelajaran berakhir. Wawancara ini digunakan untuk mengetahui secara langsung proses berpikir yang dialami mahasiswa sebagai syarat terjadinya perubahan konseptual dan untuk memperkuat hasil pengamatan yang dilakukan oleh pengamat. Berdasarkan hasil wawancara terhadap ke dua mahasiswa, dapat diketahui bahwa hasil wawancara tersebut sangat mendukung hasil pengamatan yang dilakukan oleh kedua pengamat ketika pembelajaran sedang berlangsung. Hasil wawancara tersebut lebih jelas menunjukkan bahwa ke empat mahasiswa memang benar-benar telah mengalami empat syarat yang harus dipenuhi agar terjadi perubahan konseptual terhadap konsepsi lama yang dimiliki.

\section{PENUTUP}

Berdasarkan hasil analisis deskriptif terhadap data pengamatan dan wawancara untuk mengetahui proses berpikir yang harus dialami mahasiswa agar terjadi perubahan konseptual, dapat disimpulkan bahwa model pembelajaran CCM-CCA adalah efektif untuk melakukan perubahan konseptual pada mahasiswa dari konsepsi yang salah menjadi konsepsi yang ilmiah (konsepsi fisikawan).

\section{REFERENSI}

Azizoglu, N. 2004. Conceptual Change Oriented Instruction And Students' Misconceptions Ingases. Unpublished doctoral dissertation, Middle East Technical University, Ankara,Turkey.

Baser, M. 2006. Fostering Conceptual Change By Cognitive Conflict Based Instruction On Students' Understanding Of Heat Andtemperature Concepts. Eurasia Journal of Mathematics, Science, and Technology Education, 2(2), 9614.

Byun, T.\& Lee, G. 2011. An Explanation For The Difficulty Of Leading Conceptual Change Using A Counterintuitive Demonstration: The Relationship Between Cognitive Conflict And Responses. Springer Science And Business Media B.V. 2011, Res Sci Educ DOI 10.1007/s11165-011-9234-5.

Cakir, M. 2008. Constructivist Approaches To Learning In Science And Their Implications For Science Pedagogy: A literature review.International Journal of Environmental \& Science Education, 3 (4), 193-206.

Demirciouglu, G., Ayas, A., \&Demirciouglu, H. 2005. Conceptual Change Achieved Through A New Teaching Program On Acids And Bases. Chemistry Education Research and Practice, 6, 36-51.

Fraenkel, J.R., Wallen, N.E., dan Hyun, H.H. 2012. How To Design And 
Evaluate Research In Education, 8th Edition. New York: McGraw-Hill Companies, Inc.

Gall, M.D. \& Borg. 2003. Educational Research. Boston: Pearson Education, Inc.

Jonassen, D., Strobel, J., \& Gottdenker, J. 2005. Model Building For Conceptional Change. Interactive Learning Environments. 13(1-2), April-August, 2005, 15-37.

Lee, G., Kwon, J., Park, S., Kim, J., Kwon, H., \& Park, H. 2003. Development of an instrument formeasuring cognitive conflict in secondary-level science classes. Journal of Research in ScienceTeaching, 40(6), 585-603.

Makhrus, M. 2013. Pemahaman mahasiswa tentang konsep gaya. Studi Pendahulun Tentang Model Perubahan Konseptual Dengan Pendekatan Konflik Kognitif Berbasis Pemahaman Mahasiswa Tentang Konsep Gaya: Surabaya.

Makhrus, M., Nur, M., \& Widodo, W. 2014. Model Perubahan Konseptual dengan Pendekatan Konflik Kognitif. Jurnal Pijar MIPA, 9(1), 20-25.

Makhrus, M. 2018. Validitas Model Pembelajaran Conceptual Change Model with Cognitive Conflict Approach. Jurnal Ilmiah Profesi Pendidikan, 3(1), 62-66.

Pebriyanti, D., Sahidu, H., \& Sutrio. 2015. Efektifitas Model Pembelajaran Perubahan Konseptual untuk Mengatasi Miskonsepsi Fisika pada Kelas X SMAN 1 Praya Barat Tahun Pelajaran 2012/2013. Jurnal Pendidikan Fisika dan Teknologi, 1(1), 92-96.

Posner, Strike, Hewson,\& Gertzog. 1982. Accomodation of a scienific conception: Toward a theory of conceptual change.Department of Education, Cornell University, Ithaca, New York.
Silung, S.N.W., Kusairi, S., \& Zulaikah, S. 2016. Diagnosis Miskonsepsi Siswa SMA di Kota Malang pada Konsep Suhu dan Kalor Menggunakan Three Tier Test. Jurnal Pendidikan Fisika dan Teknologi, 2(3), 95-105.

Smith, J.P., diSessa, A. A., \& Roschelle, J. 1993. Misconception reconceived: A constructivist analysis of knowledge in transition.The Journal of the Learning Science, 3, 115-163.

Tomita, M. K., 2008. Examining the influence of formative assessment on conceptual accumulation and conceptual change. Doctoral dissertation, Stanford University.

Tuqalby, R., Sutrio., dan Gunawan. 2017. Pengaruh Strategi Konflik Kognitif terhadap Penguasaan Konsep pada Materi Fluida Siswa SMAN 3 Mataram tahun ajaran 2016/2017. Jurnal Pendidikan Fisika dan Teknologi, 3(1), 8-13.

Unal, S., Costu, B., \& Ayas, A. 2010. Secondary school students' misconceptions of covalent bonding. Journal of Turkish Science Education, 7, 3-29.

Wirth, K.R. \& Perkins, D. 2008. Learning to learn. Available from: http://www.macalester.edu/geology/ wirth/CourseMaterials.html(version 16 September 2008). 